\title{
Anti-Aging Genes Improve Appetite Regulation and Reverse Cell Senescence and Apoptosis in Global Populations
}

\author{
Ian James Martins ${ }^{1,2,3}$ \\ ${ }^{1}$ Centre of Excellence in Alzheimer's Disease Research and Care, School of Medical Sciences, Edith Cowan \\ University, Joondalup, Australia \\ ${ }^{2}$ School of Psychiatry and Clinical Neurosciences, The University of Western Australia, Nedlands, Australia \\ ${ }^{3}$ McCusker Alzheimer's Research Foundation, Holywood Medical Centre, Nedlands, Australia \\ Email: i.martins@ecu.edu.au
}

Received 6 January 2016; accepted 25 January 2016; published 28 January 2016

Copyright (C) 2016 by author and Scientific Research Publishing Inc.

This work is licensed under the Creative Commons Attribution International License (CC BY).

http://creativecommons.org/licenses/by/4.0/

(c) (i) Open Access

\begin{abstract}
Appetite regulation by nutritional intervention is required early in life that involves the anti-aging gene Sirtuin 1 (Sirt 1) with Sirt 1 maintenance of other cellular anti-aging genes involved in cell circadian rhythm, senescence and apoptosis. Interests in anti-aging therapy with appetite regulation improve an individual's survival to metabolic disease induced by gene-environment interactions by maintenance of the anti-aging genes connected to the metabolism of bacterial lipopolysaccharides, drugs and xenobiotics. Interventions to the aging process involve early calorie restriction with appetite regulation connected to appropriate genetic mechanisms that involve mitochondrial biogenesis and DNA repair in neurons. In the aging process as the anti-aging genes are suppressed as a result of transcriptional dysregulation chronic disease accelerations and connected to insulin resistance, non-alcoholic fatty liver disease (NAFLD) and neurodegenerative diseases such as Parkinson's disease and Alzheimer's disease. Interests in the gene-environment interaction indicate that the anti-aging gene Sirt 1that regulates food intake has been repressed early in the aging process in various global populations. The connections between Sirt 1 and other anti-aging genes such as Klotho, p66Shc (longevity protein) and Forkhead box proteins (FOX01/ FOX03a) have been associated with programmed cell death and alterations in these anti-aging genesregulate glucose, lipid and amyloid beta metabolism that are important to various chronic diseases.
\end{abstract}

\section{Keywords}

Anti-Aging Genes, Appetite, Environment, Nutrition, Senescence 


\section{Introduction}

The hypothalamus is involved with many biological functions and includes appetite and body weight control, feeding, emotion, memory, thermoregulation, fluid balance and insulin regulation [1]-[3]. The hypothalamic nuclei that are involved in food intake include the arcuate nucleus, the paraventricular nucleus, the lateral hypothalamic area, the ventromedial nucleus and dorsomedial nucleus. Arcuate nucleus neurons at the bottom of the hypothalamus near the third ventricle have direct contact with peripheral satiety factors like leptin and insulin. Neurons in the hypothalamus are responsible for various connections to other brain regions and one of the important functions of the hypothalamus is control of the daily light dark cycle. The suprachiasmatic nucleus (SCN) that coordinate the neuronal, humoural systems and the circadian rhythms activate the arcuate nucleus that releases neuropeptide Y (NPY) and agouti related protein (AgRP) that control physiological functions (body) temperature, melatonin release, glucocorticoid secretion and behavioural functions (feeding and memory). The SCN and peripheral oscillators are altered by food availability with calorie restriction important in the maintenance of the SCN and the synchrony of the peripheral clocks. The neurons in the hypothalamus (appetite centre) are sensitive to apoptosis and become senescent early in life with relevance to global chronic diseases such as non-alcoholic fatty liver disease (NAFLD), obesity and diabetes.

In neurodegenerative diseases such as Parkinson's disease (PD) and Alzheimer's disease (AD) neurons in specific regions of the brain become apoptotic later in life but may not involve the neurons in the appetite centre. Neurodegenerative diseases such as PD and AD have become the cornerstone of brain research with appetite dysregulation and insulin resistance now closely connected to these diseases. Early neuron transcriptional dysregulation that involves the SCN leads to food intake disorders and it cannot be excluded that neurons in the appetite centre are defective early in life in global populations with appetite dysregulation associated with neurodegenerative diseases such as PD and AD. Appetite dysregulation is connected to the anti-aging gene Sirtuin 1 (Sirt 1) that is connected to the circadian rhythm with effects on the endocrine and metabolic systems that involve diseases of the adipose tissue, heart, liver, pancreas and brain [4]-[6]. Neuron apoptosis and survival [7]-[10] is determined by Sirt 1 and other anti-aging genes and interventions that prevent down regulation of anti-aging genes may allow appetite regulation with prevention of other chronic diseases. The rise in NAFLD in global populations [11] [12] has required early intervention with connections to the severity of diseases such as obesity, diabetes and neurodegenerative diseases. Interests in the calorie restriction with stabilization of antiaging genes have accelerated in recent years to delay and prevent programmed cell death linked to the various chronic diseases (Figure 1). Interventions such as diet and lifestyle in chronic diseases such as obesity, diabetes and cardiovascular disease involve abnormal post-prandial lipid metabolism [13] [14]. Diet is strongly associated with insulin and insulin like growth factor-1 (IGF-1) with cell senescence (mitochondrial apoptosis) and genotoxic stress linked to the global NAFLD and neurodegeneration [15]-[21].

Interest in genomics that leads to the identification of novel genetic pathways assists in the treatment of various chronic diseases with the new knowledge that may delay early programmed cell death pathways in cells. Nutritional interventions that are controlled by the consumption of a low calorie diet indicate the maintenance of connections between Sirt 1 and other anti-aging genes such as Klotho, p66Shc (longevity protein) and FOXO1/ FOXO3a that have been connected to the cell death by effects on glucose, lipid and amyloid beta metabolism. These anti-aging genes in neurons are involved in transcriptional regulation with effects that are important to SCN control of food intake and to the survival and stability of neurons. High fat diets that induce cell senescence are linked to cell transformation and are associated with liver cell dysfunction (NAFLD), adipogenesis disorders (obesity) and other organ diseases (Figure 1). The severity of endocrine and metabolism disorders are associated with poor neuron survival with early neuron transformation that leads to appetite dysregulation with overeating linked to metabolic disease. Major advances in the early diagnosis of diseases such as NAFLD and neurodegenerative disease associated with obesity and diabetes are required. Diagnostic blood assays such as plasma cholesterol measurements may not determine early senescence and programmed cell death [22] and extensive blood testing that is now underway in global populations may not be relevant to liver cell or neuron apoptosis (neurodegenerative diseases). The role of diets that control the absorption of bacterial lipopolysaccharides (LPS) are critical to prevent NAFLD and neurdegeneration [23] and the repression of anti-aging genes are possibly linked to LPS with the acceleration of appetite dysregulation and chronic diseases. The effects of LPS may also interfere with IGF-1 mediated expression of anti-aging genes with IGF-1/p53 transcriptional regulation linked to Sirt 1 regulation of cell survival in aged and stressed cells [15]-[21]. To improve appetite dysregulation 


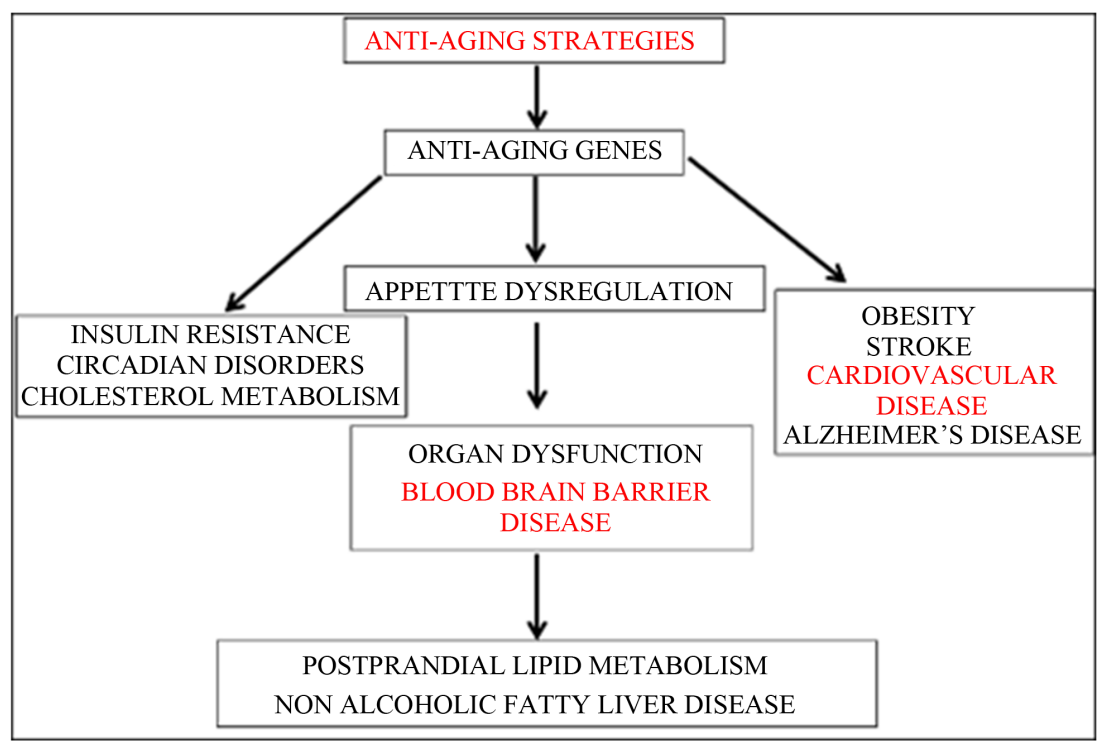

Figure 1. Anti-aging strategies involve the maintenance of appetite regulation and insulin resistance that are connected to the anti-aging genes that are suppressed early in life. Appetite dysregulation accelerates abnormal post-prandial lipid metabolism and NAFLD in global populations and early intervention is required to prevent the severity of diseases such as obesity, diabetes and neurodegenerative diseases. Appetite maintenance improves the endocrine and metabolic system that is connected to blood brain barrier (BBB) disease and various organs diseases.

and prevent overeating that is linked to gene-environment effects (stress) on metabolic disease the maintenance of the apelinergic pathway [24] early in life is essential. Nitric oxide (NO) is involved in appetite regulation and NO disturbances have been reported in various chronic diseases [25]. Diets that are high in NO override cell NO maintenance that is controlled by Sirt 1 relevant to endocrine, metabolic disease and thrombosis [24]-[27]. The effects of stress and xenobiotics (environment) are associated with cell NO disturbances that prevent the reversal of cell senescence (Figure 2). The nutritional diets that maintain the anti-aging genes and NO cell homeostasis possibly involve Sirt1/IGF-1 [29]-[36] with the effects of dietary LPS involved in the NO dyshomeostasis, neuron senescence and apoptosis.

Zinc deficiency and chronic disease has become important with zinc levels relevant to hormone bioactivity [3], Sirt 1 activity [28] and IGF-1 functions [37] [38]. Zinc supplementationhas become important to LPS toxicity with relevance to inflammation in various global populations [39] [40]. Appetite regulation has been associated with various neuropeptides such as brain derived neurotrophic factor (BDNF) and NPY, hormones such as insulin, adiponectin, leptin and various intestinal peptides [3] [41]-[43]. The role of zinc and Sirt 1 that involved in the regulation of the anti-aging genes has become important since repression of these genes do not maintain the action of the various neuropeptides, hormones and intestinal factors involved in appetite regulation with relevance to chronic diseases. Anti-aging therapy that maintains appetite regulation improves an individual's survival against autonomous disease induced by the environment (bacterial lipopolysaccharides, drugs, xenobiotics) in various communities. Diets that are nutritional activate cellular anti-aging genes with the prevention of cell senescence and apoptosis. Appetite regulation maintains the autonomic innervation of the liver by the brain with the maintenance of rapid post-prandial lipid metabolism [13] [14] and the prevention of diseases of the adipose tissue, heart, and pancreas.

\section{Repression of Anti-Aging Genes Determine Food Intake Regulation, Insulin Resistance and Neurodegenerative Disease}

Overnutrition in chronic disease is involved with central nervous system dysregulation of neuropeptides with abnormal peripheral hormone signalling from the pancreas (insulin), adipose tissue (leptin and adiponectin) and gastrointestinal tract (neuropeptides) involved in chronic diseases. The increases in global chronic disease in the 


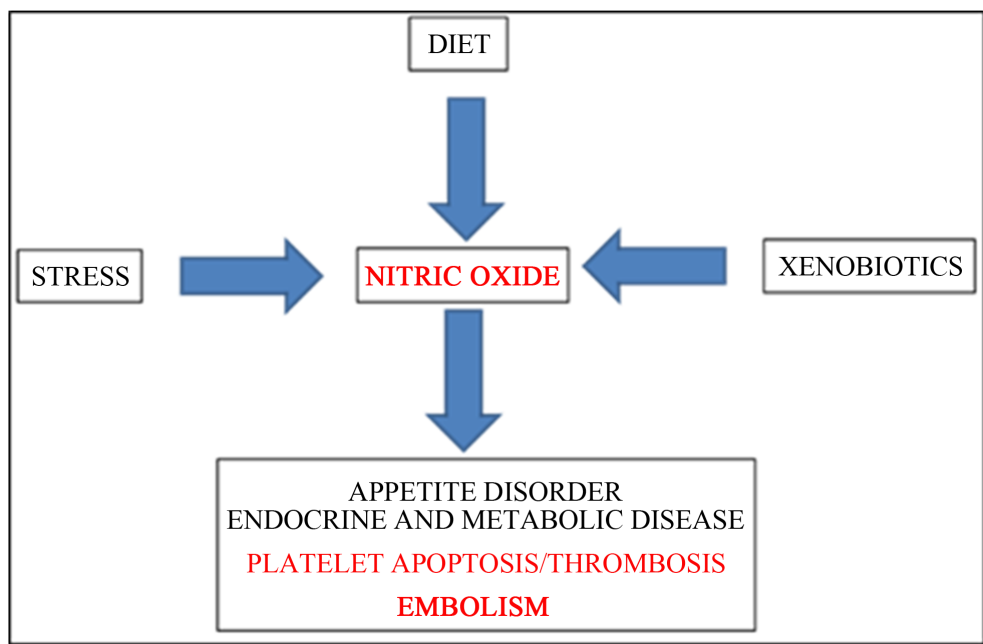

Figure 2. The acceleration of chronic diseases involve NO disturbances linked to stress, consumption of unhealthy diets and xenobiotics (gene-environment interactions). Endocrine and metabolic diseases are linked to appetite dysregulation with NO disturbances that involve defective apelinergic pathways. Nutritional diets maintain the anti-aging genesand NO cell homeostasis with the importance of Sirt1/IGF-1 interactions in NO homeostasis, neuron senescence and apoptosis. Sirt 1 is involved with the circadian rhythm and platelet apoptosis with relevance to thrombosis and embolism.

past 20 years have indicated that insulin resistance and organ suicide are closely connected. The role of the mitochondria in organ function is critical with increased mitochondrial apoptosis with accelerated aging. The role of anti-aging genes in organ disease has become of central interest to maintain mitochondria functions and the identification of longevity genes that determine their function is critical to the maintenance of chronic diseases. The association between senescence and chronic disease now indicate that the anti-aging genes have been suppressed (autonomous disease) and insulin resistance, IGF-1 levels and neuropeptide disturbances are closely connected to mitochondria aging and cell senescence. Defective anti-aging genes are associated with glucose dysregulation with inhibition of insulin signalling involved with mitochondrial apoptosis. In SCN neurons within the brain the anti-aging genes that are involved with appetite regulation become altered by altered gene expression and abnormal posttranscriptional regulation closely connected to appetite dysregulation. The SCN synchrony between neurons is essential to maintain circadian rhythms and disturbances between neurons are associated with autonomous neuron disease linked to the anti-aging gene repression and liver dysfunction.

The gene that is involved in the regulation of food intake is Sirtuin 1 (Sirt 1) that is linked to life span, obesity and cardiovascular disease with effects on NAFLD, inflammation, energy metabolism, cognition, mitochondrial biogenesis, neurogenesis, glucose/cholesterol metabolism and amyloidosis. Sirt 1 is a nicotinamide adenine dinucleotide $(\mathrm{NAD}+)$ dependent class III histone deacetylase (HDAC) that targets transcription factors to adapt gene expression to metabolic activity and is involved in the deacetylation of the nuclear receptors with its critical involvement in insulin resistance. Sirt 1 is also involved in telomerase reverse transcriptase and genomic DNA repair with its involvement in telomere maintenance that maintains chromosome stability and cell proliferation. Sirt1 is essential for neurogenesis and calorie restriction activates Sirt1 with effects on longevity by modulation of phosphoinositide 3 kinase pathways and age associated cardiovascular changes. Tissue nuclear receptors undergo deacetylation of histone and non-histone targets by Sirt 1 that targets transcription factors peroxisome proliferator-activated receptor-gamma coactivator (PGC-1 alpha), p53, pregnane $\mathrm{x}$ receptor (PXR) to adapt gene expression to metabolic activity, insulin resistance and inflammation. Sirt 1 is linked to glucose regulation with the involvement of Forkhead box protein O1 (FOXO1) deacetylation (apoptosis) that involve p53 transcriptional dysregulation and peroxisome proliferator activated receptor (PPAR) gamma nuclear receptor. Furthermore Sirt 1/p53 interactions may regulate adipocytokines and immune responses that may be important to NAFLD, obesity and neurodegeneration. Interests in calorie restriction, appetite regulation and neurodegeneration that involve Sirt 1 mediated regulation of other anti-aging genes involve p53 and FOXO deacetyla- 
tion that has attracted interest in relation to autonomous disease of the brain and liver. In these tissues Sirt 1 is an important gene involved in maintenance of the mitochondria and deacetylation of the transcriptional factor FOXO3a that represses Rho-associated protein kinase-1 gene expression with activation of the non amyloidogenic $\alpha$-secretase processing of the amyloid precursor protein and reduction of amyloid beta (A $\beta)$ generation in neurons. Sirt 1 is also involved with hepatic cholesterol regulation with effects on liver nuclear receptors involved with cholesterol flux and metabolism. Overnutrition is associated with the repression of Sirt 1 and other anti-aging genes (Figure 3) such as Klotho, p66Shc (longevity protein) and FOXO1/FOXO3a that is now connected to autonomous diseases of the brain and liver with SCN disturbances induced by Sirt 1 repression and IGF-1 dysregulation involved in programmed cell death relevant to various chronic diseases such as obesity, diabetes, $\mathrm{PD}$ and $\mathrm{AD}$.

\subsection{Klotho}

The klotho (KL) gene is composed of 5 exons and encodes a type-I single pass transmembrane protein (1014amino acid-long), short intracellular domain (10-amino acidlong). The extracellular domain is composed of two domains, termed KL1 and KL2, with weak homology. Klotho knockout mice have a short life span with increased oxidative stress associated with atherosclerosis, osteoporosis, infertility, and cognitive decline. The gene for the mammalian KL has two transcripts encode a long type I transmembrane protein and a short secreted protein that is released from the cell membrane and found in the serum and cerebrospinal fluid (CSF) [44] [45]. Sirt 1 and its close involvement as a histone deacetylase may be involved with Kotho gene expression and Sirt 1 downregulation may be intimately involved in the secretion and release of the protein into the serum or CSF. Resveratrol is closely involved in Sirt 1 upregulation and studies indicate that Klotho gene expression and secretion is upregulated by resveratrol [46]. Klotho gene has been identified as an important regulator of age related diseases and is involved with cell senescence by upregulation of p21 [47]. Klotho is an anti-aging gene and in Klotho-deficient mice Klotho has been associated with a premature aging-like syndrome. These results demonstrate that Klotho normally regulates cellular senescence by repressing the p53/p21 pathway that is activated by DNA damage and causes G(1)-phase arrest in mammalian cells. Klotho has been reported as a secreted Wnt antagonist and a tumor suppressor [48]. Epigenetic silencing of klotho has been shown as a major pathway with the involvement of histone deacetylation in the transcriptional repression of Klotho is correlated with promoter

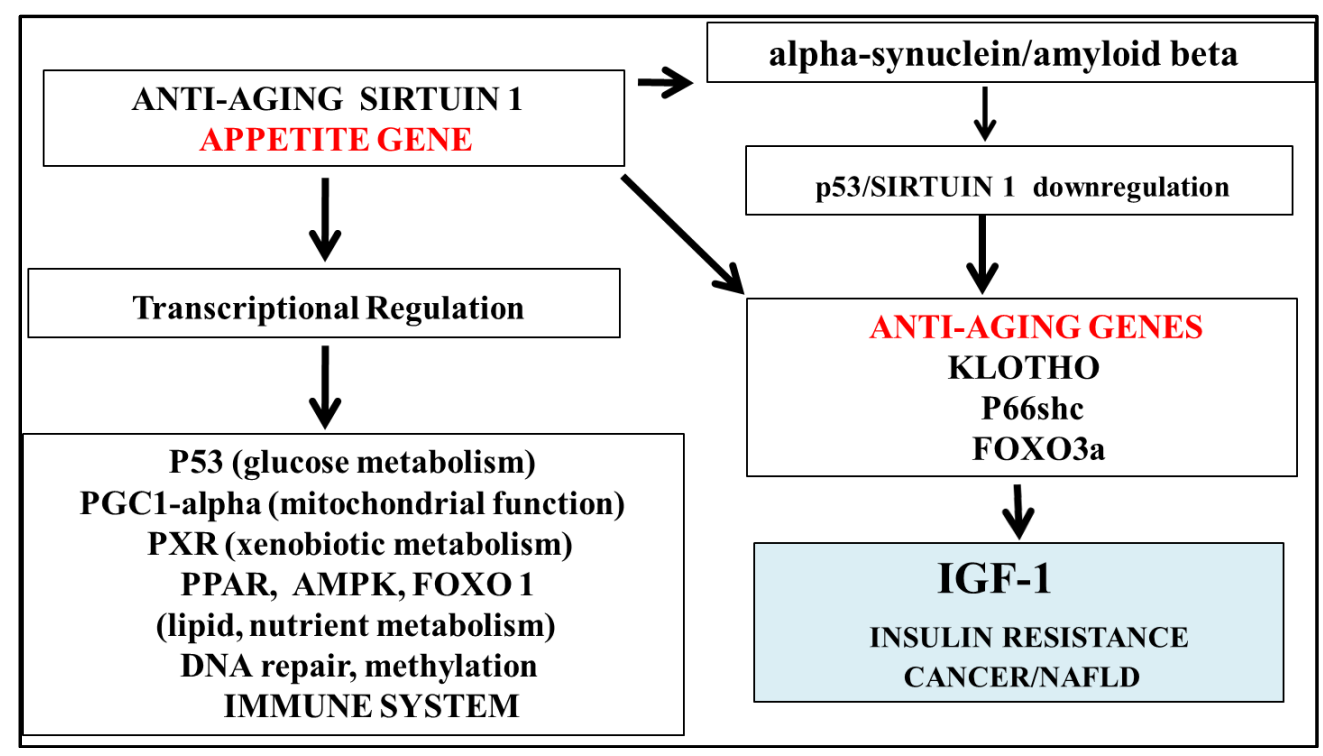

Figure 3. The anti-aging gene Sirt 1 is associated with transcriptional regulation and linked to insulin resistance, cancer and NAFLD. Sirt 1 regulation of p53, PGC1-alpha, PXR, PPAR, AMPK, FOXO1 involve nutrient, xenobiotic metabolism with relevance to DNA repair and the immune system. Transcriptional regulation of Sirt 1/p53 interactions are associated with alpha synuclein and amyloid beta interactions with the abnormal p53 transcriptional regulation of the anti-aging genes (Sirt 1, Klotho, p66Shc (longevity protein), FOXO1/FOXO3a) associated with IGF-1 and cancer. 
CpG hypermethylation and linked to Sirt 1 gene silencing that involve CpG island methylation. Klotho protein has been indicated to be a hormone that inhibits the intracellular insulin/IGF-1 signaling cascade [49] [50]. In other studies Klotho has been shown not inhibit IGF-1 and/or insulin signaling in various cells such as HEK293, L6, and HepG2 cells and indicate against the role of Klotho in insulin resistance as an important regulator of aging. Klotho gene expression was not associated with telomere length and the association with aging via other mechanisms [51]. Klotho has been associated with cognition [52] and chronic kidney disease via the fibroblast growth factor 23 but klotho levels have remained unchanged [53].

\section{2. p66Shc}

The gene SHC1 is located on chromosome 1 and encodes 3 main protein isoforms: p66Shc, p52Shc and p46Shc and differ in molecular weight. p66Shc, a $66 \mathrm{kDa}$ proto-oncogene Src collagen homologue (Shc) adaptor protein is a longevity protein and has many effects involved with cell receptor tyrosine kinase signal transduction, nutrient metabolism and increased levels of p66Shc (Ser phosphorylation) have been shown to block mitosis, inhibit glucose metabolism and associated with the regulation of reactive oxygen species induced cell apoptosis [54]-[57]. p66Shc antagonizes insulin and mTOR effects which limits glucose uptake and inhibits anabolic metabolism [58] [59]. The p66shc protein plays key role in oxidative stress, stroke, metabolic disease in various organs and tissues in obesity and diabetes [60]-[64]. The p66Shc isoform has inhibitory effects on the Erk pathway [65] in skeletal muscle myoblasts, actin cytoskeleton polymerization and glucose transport. p66Shc inhibits ERK1/2 activity and antagonize mitogenic and survival abilities of T-lymphoma Jurkat cell lines. The MAPK/Erk signaling cascade is activated by a wide variety of receptors involved in growth and differentiation including receptor tyrosine kinases (RTKs), integrins, and ion channels. Oxidized lipids and LDL have been shown to stimulate p66Shc expression that is associated with abnormal redox balance, endothelial dysfunction and cardiovascular disease [66]-[68]. p66Shc is involved with the expression of p53 and p53 isoform (p44/p53), oxidative stress and G2M cell cycle arrest [69]-[71]. The induction of angiotensin II regulated p66Shc is controlled by stress activated p53 and indicates that post transcriptional regulation by p53 of p66Shc is essential for endothelium dependent vascular relaxation [72]. Sirt 1 is primarily involved in the deacetylation of p53 with control of p66Shc cellular senescence associated with the progression of NAFLD. Repression of p66Shc expression by Sirt 1 has been shown to be involved with liver injury and hyperglycemia induced endothelium dysfunction [73]. Palmitic acid is an inhibitor of Sirt 1 and palmitate has been shown to increase p66Shc (Ser phosphorylation) in pancreatic beta cells [74]. p53 is closely involved with the palmitate-induced increase in p66Shc expression and beta cell apoptosis. Sirt 1 that is actively involved in $\mathrm{A} \beta$ metabolism in neurons and $\mathrm{A} \beta$ has now been connected to the phosphorylation of p66Shc at the serine 36 residue with increased oxidative stress that leads to cell death [75] [76]. Antioxidants have been shown to be involved with reduced oxidative stress by interfering with the phosphorylation of p66Shc. Sirt 1 has effects on brain and liver alpha-synuclein and A $\beta$ metabolism closely linked metabolic disease [77] [78] with effects of p53 transcriptional regulation by intracellular alpha-synuclein and $\mathrm{A} \beta$ metabolism in the liver and brain linked to the regulation of anti-aging genes and cellular apoptosis [78] [79].

\subsection{FOX03a}

FOXOs belong to the $\mathrm{O}$ subclass of the Forkhead family of transcription factors which are characterized by a Forkhead DNA binding domain. There are three main proteins (FOXO1, FOXO3a and FOXO4) from which FOXO3a protein is considered to be a regulator of cancer and aging [80]-[83]. FOXO1 proteins are involved with adipocyte lipid metabolism and ROS-dependent cascades. FOXO3a is found in the nucleus but is redistributed to the cytosol by the actions of ROS and activation of this pathway (insulin/insulin-like growth factor-1 (IGF-1)/phosphatidylinositol-3 kinase (PI3K)/Akt/FOXO3a) is associated with senescence [84]. p66Shc participates in Akt signaling pathway and is involved with inactivated FOXO3a and ROS effects that involve activated p38 and JNK and inactivated by Akt kinase in cells. Sirt 1 has been shown to deacetylate FOXO3 and FOXO4 with the regulation of FOXO-induced apoptosis and cell-cycle arrest not connected to p53 deacetylation. Sirt 1 has been shown to interact with FOXO3a and induce cell apoptosis [85] [86]. Nuclear Sirt 1 actively involved in $\mathrm{A} \beta$ metabolism and possibly regulates FOXO associated senescent effects with control of cell survival. Klotho has been shown to activate FOXO and to inhibit the insulin/IGF-1/PI3K/Akt signaling cascade. The connections between Sirt 1 and Kotho for cell senescence possibly are connected via FOXO1/FOXO3a mediated glucose 
homeostasis and ROS pathways. Bacterial lipopolysaccharides (LPS) are involved in the repression of Sirt 1 with the actions on other anti-aging genes. Zinc is the activator of Sirt 1 function with LPS closely connected to zinc deficiency with zinc supplementation essential to reduce LPS toxicity [38] [39]. Sirt 1's effects on cellular cholesterol homeostasis is by its deacetylase activity and ubiquitination of liver X receptor (LXR) proteins with the regulation of ATP-binding cassette transporter (ABCA1) and sterol regulatory element-binding protein 1 cinvolved in cell cholesterol homeostasis [78] [79]. LPS interferes with Sirt 1 and ABCA1 interactions by inhibition of cholesterol flux via LXR-ABCA1 pathways [78] [79]. Sirt 1 regulation of PGC1 alpha is well understood with PGC1 alpha involved in the inactivation of prostaglandain E2 (PGE2) with fat accumulation [11]. LPS is involved in the biosynthesis of PGE2 with LPS effects in the liver and other cells that override Sirt 1and PGC1 alpha effects in these cells [87] [88]. The major effects of Sirt 1 as a deacetylase is regulation of the transcription factor p53 involved in the regulation of cell glucose and cholesterol metabolism [79]. LPS is involved in the post-transcriptional regulation of p53 with interference of Sirt 1/p53 cell regulation pathways involved in cell maintenance [79]. LPS induces mitochondrial apoptosis with toxic effects on the SCN neurons involved with appetite regulation that involve Sirt 1 dysregulation linked to anti-aging genes [78] [79]. IGF-1 levels and its connections to Sirt 1 and the anti-aging genes possibly involve corruption by LPS with LPS effects that involve dysregulation ofcircadian regulation of IGF-1 with IGF-1 effects on nuclear genes (cancer) and mitochondria within cells [17]-[19] [89]-[91]. Sirt 1 and its regulation of the SCN and appetite centre are inhibited by LPS via interference of the Sirt 1/p53 pathways that involve the other anti-aging genes.

\section{Dysregulation of Neuropeptides and Endocrine Hormones by LPS Determine Appetite and Metabolism Disorders}

The SCN in the brain is closely involved with appetite regulation and LPS induced posttranscriptional regulation in neurons is now closely connected to appetite dysregulation. The SCN synchrony between neurons is essential to maintain circadian rhythms and disturbances between neurons are associated with autonomous neuron disease linked to appetite dysregulation. LPS has a number of effects on various cells and tissues in the periphery and in the brain. LPS induces dyslipidemia and NAFLD with effects on apolipoproteins (apo E, apo AI), acute phase proteins, cytokines, albumin, alpha synuclein and amyloid beta [77] [78]. Its preference for binding to cholesterol and sphingomyelin sites on cell membranes indicates its role in the electrostatic interaction of amyloid beta [23] [77]. LPS has marked effects on receptors and on the astrocyte-neuron interaction with the induction of neuroinflammation [77]. LPS effects on the sleep/wake cycle determines food intake regulation and LPS effects on appetite regulation involves Sirt 1 repression and alpha synuclein/IGF-1 metabolism [78] [92]-[95]. Neurons in the hypothalamus are responsible to various brain regions and LPS induction of nuclear, mitochondria and cell membrane interactions induces autonomous cell behaviour with appetite dysregulation linked to reorganization cell signalling and astrocyte-neuron synchrony in the brain. Autonomous disease interferes with the effects of neuropeptides and hormones that are no longer effective and are now connected to nuclear receptors dysfunction associated with the anti-aging genes. Appetite regulation has been associated with various neuropeptides such as BDNF and NPY, hormones such as insulin, adiponectin, leptin and various intestinal peptides [96].

The interests in LPS in the induction of autonomous neuron disease involve inflammation with the connections to poor neuropeptide/receptor and peripheral hormones interactions that promote appetite dysregulation in the brain. NO has been clearly linked to food intake regulation and autonomous neuron disease induced by LPS is relevant overeating and metabolic disease in global populations (Figure 2). The effects of LPS induce mitochondrial apoptosis with NO dyshomeostasis [97]-[100] and corrupt appetite regulation by interference with neuropeptides and peripheral hormones that are also involved in the maintenance of mitochondrial stability. The effects of LPS on nuclear Sirt 1 repression in neurons disturb Sirt 1 regulation of cell NO metabolism with Sirt 1 linked to mitochondrial biogenesis [79]. The effects of LPS in the brain and the liver corrupt the autonomic innervation of the liver by the brain [101] with the liver clocks under autonomous regulation with sensitivity to disturbed post-prandial metabolism, liver steatosis and NAFLD. Interest in metabolic disorders indicate that the communication between the gastrointestinal tract neuropeptides involve the hypothalamus and brain stem [3].

These regions of the brain integrate peripheral signals such as various factors released from the gut and adipose tissue that have effects on neuronal activity of the hypothalamus and brain stem that control appetite regulation. In response to food intake various gut and adipose tissue hormones have effects on the hypothalamus that release various neuropeptides that effect appetite, food intake and energy balance. Cholecystokinin (CCK) is an 
intestinal hormone and after a meal CCK levels rise to inhibit food intake. Other peptides involved in appetite regulation include glucagon like peptide (GLP-1) that increases in the blood plasma released from the L cells of the gastrointestinal tract. Pancreatic islet beta cells release insulin and another peptide referred to as amylin is released with relevance to reduced food intake. Other proglucagon cleavage peptides including oxyntomodulin (OXM) and peptide YY (PYY) are secreted with GLP-1 in response to high calorie foods. Pancreatic polypeptide (PP) is secreted from the pancreatic islets and is similar in structure to PYY with reduction in food intake after administration to rodents and humans. PP has effects on gastric ghrelin and gene expression of hypothalamic peptides such as NPY and AGRP that control food intake. Ghrelin is 28 amino acid peptide hormone and has been characterized as an appetite stimulating hormone with effects on appetite control related to hypothalamic NPY/AgRP neurones which express the ghrelin receptors [3].

Future therapies that involve control of body size and adiposity will involve assessment of diets that reduce LPS absorption [23] with relevance to LPS effects on the hypothalamus and on the poor regulation of various intestinal and brain neuropeptides that influence appetite regulation. Influence on appetite regulation and feeding are also related to leptin, melanortin, adiponectin, melanin concentrating hormone (MCH), orexins and endocannabinoids that communicate with peripheral signals such as nutrients (glucose, amino acids, fatty acids) and gastrointestinal peptide hormones such as CCK and ghrelin. Thyroid hormones may act directly on the hypothalamic appetite circuits and signalling factors such as thyroid stimulating hormone, triiodothyronine (T3) and thyroxine (T4) have recently shown to directly influence food intake. Hypothalamic control of appetite regulation and energy expenditure not only involves the hypothalamus but also the hypothalamic pituitary axis (HPT). Recent evidence indicates that the HPT axis can control food intake and effects on appetite and body weight is mediated by thyroid hormones and LPS has become important to appetite regulation [102] [103]. Interests in the neuroendocrine system, energy metabolism and peripheral cholesterol metabolism have increased with the strong genetic identification andinvolvement NPY in plasma cholesterol regulation.

The CNS and its control of lipidmetabolism has identified hypothalamic NPY with evidence that NPY has effects onY1 receptors to promote hepatic lipoprotein secretion to promote VLDL secretionvia the sympathetic nervous system [104] [105] and on Y2 receptors to promote feeding. Sirt 1 regulation of BDNF [106]-[108] has been shown (Figure 4) and associated with altered NPY levels in the brain [109] [110] and several studies have indicated its involvement in neuronal plasticity, behaviour, appetite control andbody weight regulation. BDNF is involved in the regulation of food intake and the levels of BDNF controlled by high fat diets. In mature neurons the BDNF peptide is involved with the regulation of synaptic plasticity and neuro transmission in the peripheral

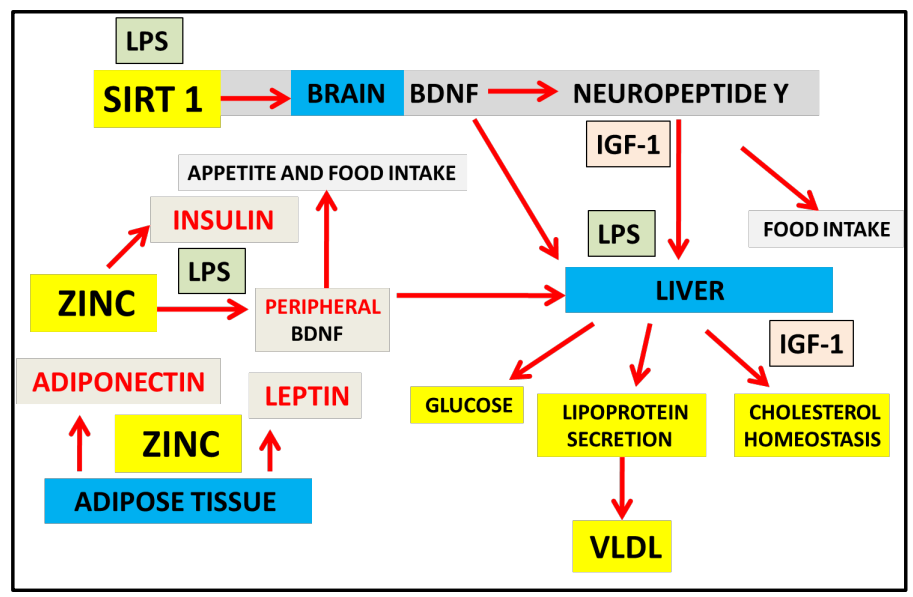

Figure 4. Bacterial LPS suppresses Sirt 1 expression with effects on neuropeptides such as brain derived neurotrophic factor, neuropeptide $\mathrm{Y}$ and IGF-1 that are involved in the appetite regulation (food intake) in the brain and in the periphery LPS interrupts hepatic glucose, lipoprotein and cholesterol metabolism. LPS is involved in cell zinc homeostasis with the importance of zinc relevant to the maintenance of Sirt 1 activity and the function of hormones such as insulin and the adipokines (adiponectin, leptin) involved in appetite regulation in the hypothalamus. 
and central nervous system. BDNF is involved in regulation of CB1 receptor expression and the proliferation, survival and maintenance of neurons. In individuals with the metabolic syndrome Sirt 1 downregulation is possibly related to BDNF levels [111], IGF-1 levels and abnormal NPY regulation involved with appetite dysregulation and neurodegeneration.

Zinc deficiency has marked effects on brain zinc homeostasis and is associated with alterations in behaviour, learning and mental function. Under stress, anxiety and depression disorders zinc levels alter with marked effects on health and well being of the individuals. Stress has been linked to body weight regulation and evidence suggests zinc's involvement in the molecular mechanisms of brain function and appetite control. Zinc is involved with regulation of leptin, insulin and adiponectin levels, adipose tissue cytokines (interleukin 2 and tumour necrosis factor) with long term effects on appetite regulation in the brain.

In zinc deficiency NPY levels in the hypothalamus are increased and release of NPY from the paraventricular nucleus is impaired with effects on regulation of food intake [112] [113]. In zinc deficiency NPY is unable to bind to its receptors to intiate an orexigenic response. Zinc is involved in the expression of brain BDNF and NPY synthesis and its effects on insulin, leptin and adiponectin [3] in the peripheryindicates its role in the close relationship between appetite control and cholesterolhomeostasis. Zinc is an activator of Sirt 1 and plays a critical role in the biology of p53 that is involved in the binding of p53 to DNA [114]. Interests in alpha-synuclein and food intake have increased [92] [93] and its relevance to p53 transcriptional regulation has been shown with LPS involvement [78] [79]. LPS regulation of apo E (23) has become important with relevance to apo E suppression of food intake [115]-[117] and LPS effects on leptin synthesis may determine appetite regulation [118] [119]. Leptin is a $16 \mathrm{kda}$ protein identified in 1994 (14) is synthesized by fat cells and acts as a satiety factor at the hypothalamus mediated through the leptin receptor. The amount of leptin released is proportional to the size of adipose tissue and regulates food intake. LPS has effects on adipose tissue with release of free fatty acids associated with insulin resistance [120]. Dietary fat that promotes LPS absorption may determine apo E and leptin synthesis in the hypothalamus with relevance to chronic automomic disease that involveszinc deficiency, appetite dysregulation and insulin resistance.

\section{Anti-Aging Therapy Involves Reversal of Appetite Disorders in Autonomous Chronic Diseases}

In the aging process appetite dysregulation (overeating) is connected to the suppression of the anti-aging genes as a result of transcriptional dysregulation. Interests in the gene-environment interaction [121] [122] indicate that the anti-aging gene Sirt 1 that regulates food intake is repressed early in the aging process in various global populations. Repression of Sirt 1 and other anti-aging genes such as Klotho, p66Shc (longevity protein) and FOXO1/FOXO3a lead to abnormal regulation of glucose, lipid and amyloid beta metabolism that are associated with programmed cell death in the liver and brain. Dietary effects on stress sensitive anti-aging genes (repression) may be associated with Sirt 1 downregulation with appetite dysregulation and accelerated disease progression. Anti-aging therapy that maintains appetite regulation improves an individual's survival against autonomous disease induced by the environment in various communities. Bacterial lipopolysaccharides, drugs, and xenobiotics consumed early in life induce autonomous chronic disease and corrupt the Sirt 1 circadian clock gene with dysregulation of other cellular anti-aging genes now associated with cell senescence and apoptosis. Furthermore the lack of ingestion of nutritional doses of phosphatidylinositol (appetite regulation) leads to liver steatosis and acceleration to NAFLD. In the current global NAFLD in developing countries [122] [123] the induction of autonomous liver disease by consumption of high calorie diets that contain LPS, xenobiotics and drugs is now relevant to neurodegenerative diseases such as PD and AD. LPS and xenobiotics inactivate liver cells (autonomous liver disease) with relevance to the defective peripheral sink abeta clearance pathway that is now relevant to many chronic diseases [11] [124] that before may have been previously only associated with neurodegeneration [77]. The role of anti-aging genes in various communities in the developing world may be altered early in life with the acceleration of various diseases [11]. In the developed world the xenobiotic free diet and appropriate zinc consumption may activate hepatic nuclear receptors and with the metabolic syndrome the malfunction of various organ diseases may not be associated with the insulin resistance epidemic [125]. To maintain the cell anti-aging gene mechanisms and prevent early programmed cell death diets that are very low carbohydrate diets need to be ingested to avoid the intestinal absorption of LPS into the blood that is found in various foods [14]. The low calorie diet will maintain the nuclear Sirt 1 activity with relevance to p66Shc 
mechanisms that are sensitive to the ingestion of high palmitic acid and leads to cell cycle dysregulation with cell apoptosis [74] [126]. Short chain fatty acids (SCFA) have become important to appetite regulation with the consumption ofacetate, propionic acid and butyric acid at therapeutic doses applicable to central appetite regulation [127] [128]. Butyric acid has been associated with the inhibition of zinc associated HDACs and administration of butyric acid doses in man for the reduction of alpha-synuclein and $\mathrm{A} \beta$ oligomers [78] [129] may inhibit the zinc sensitive HDACs such as Sirt 1 involved in cell NO homeostasis [129]. LPS sensitive butyric acid events have been associated with $\mathrm{T}$ cell apoptosis and cancer (Figure 5) with butyric acid derivatives important to cancer treatment [130]. The use of SCFA in nutritional diets has attracted interest to appetite regulation but the doses of the SCFA have become of concern for use in man and administration of butyric acid may need to be assessed with relevance to plasma LPS levels that may corrupt the neuroprotective effects of a ketogenic diet [131].

Sirt 1 activators (nutrients) and inhibitors (drugs, alcohol) have been previously described [11] and their consumption in various countries will determine nuclear receptor function and insulin resistance and determine the origin of autonomous chronic disease associated with early liver dysfunction linked to organ disease progression. Diets that are high in NO override the Sirt 1/ p66Shc regulation of cell NO (Figure 5) and mitochondrial apoptosis linked to cell autonomous disease are possibly associated with the acceleration of obesity, diabetes and neurodegeneration [25] [132]. The major interest in cell anti-aging genes is relevant to specific dietary intake that allows Sirt 1 cell function to belinked to therapeutic neuropeptide and endocrine responses that lead to the maintenance of anti-aging cellprocesses with the prevention of NO related apoptosis [133]-[135]. Interactions between cells in various tissues such as the liver and brain have become important with the brain involved in the autonomic regulation of liver function. The liver clock [136] may override the automonic regulation of brain control by autonomous behaviour between cells that may be induced by LPS, mycotoxins or xenobiotics [137] with dysregulation of neuropeptides and endocrine hormones. Mycotoxins, LPS and xenobiotics that may be transported to the brain may induce cell desynchrony with appetite dysregulation and overeating related to dysregulation of neuropeptides and endocrine hormones important to insulin and the IGF-1 signaling cascade. The synergism between LPS, mycotoxin and xenobiotics in diets may override the function of the anti-aging genes with the liver autonomous to brain regulation with the development of obesity and diabetes. The intestine and its release of lipid particles such as chylomicrons after a meal [14] has become important to human disease with intestinal release of lipid particles that contain LPS, xenobiotics and mycotoxins. The fat content of diet that releases the number and size of the intestinal particles has become important [138] to the function of the anti-aging genes in liver cells and food restriction (chylomicron release) that allows maintenance of anti-aging gene function is required. Under fasting conditions or timed meal conditions the release from the intestine of chylomicrons with LPS, xenobiotic or mycotoxin to the liver may allow rapid hepatic metabolism and elimination

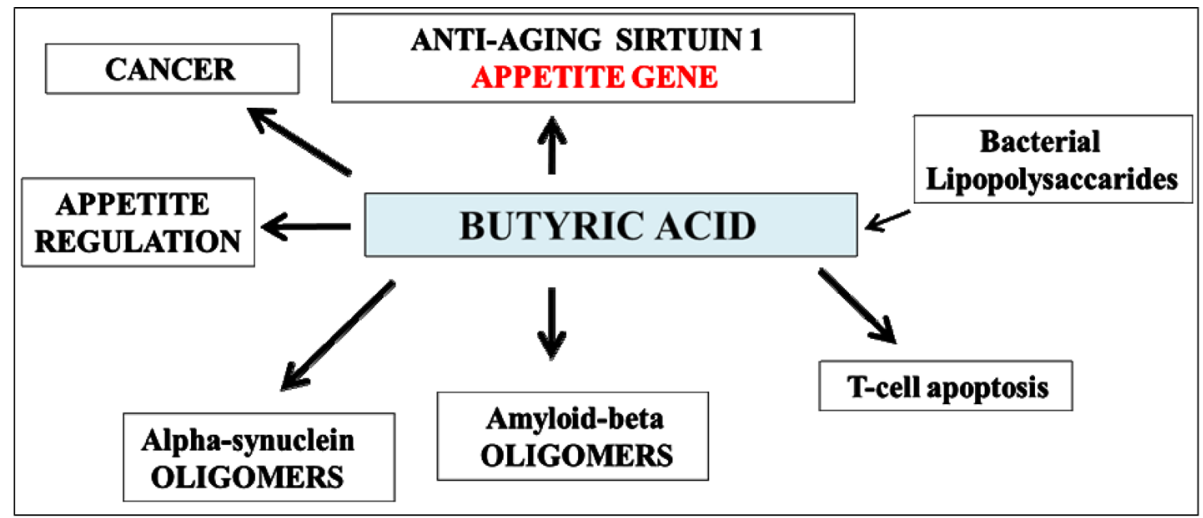

Figure 5. The short chain fatty acid butyric acid has been shown to be involved in the inhibition of Sirt 1 activity with effects of butyric acid and LPS on T cell apoptosis and cancer. Butyric acid regulation of brain appetite signals involves other short chain fatty acids such as acetate and propionic that are important to central appetite regulation. Butyric acid inhibits Sirt 1 with effects on the metabolism of alpha synuclein and amyloid beta metabolism in cells. Administration of dietary phenyl butyric acid reducesalpha synuclein and amyloid beta oligomers in the brain in mice. 
of various drugs into the bile [122] [137]. Tests for postprandial lipid metabolism in obesity indicate that in the fed and the fasting conditions dietary chylomicron remnant metabolism is defective with liver programmed cell death [14]. The various blood tests [22] and tests for postprandial lipid metabolism [14] may not allow early diagnosis of autonomous liver disease independent of appetite regulation that may be the primary disease associated with the current global obesity linked diabetes epidemic relevant to neurodegeneration [3] [22] [139]. The addition of zinc to the diet may not reverse the cell autonomy and may require the addition of various nutrients and the removal of various Sirt 1 inhibitors required for anti-aging cell processes. In the developing world, abnormal blood lipids (cholesterol, triglyceride) and liver enzymesmay not interpret the effects of LPS and mycotoxin on anti-aging genes in the liver and brain that are defective and the effects of the anti-aging therapy such as consumption of a very low carbohydrate or a low fat diet [11] are possibly able to reverse the autonomous cell behaviour (nuclear-mitochondria interactions) that is linked to the nuclear senescence with mitochondrial apoptosis [79]. The use of diet as therapy for reversal of the aging process may stabilize the apelinergic system [25] that is defective in individuals with insulin resistance and important to the optimal function of the brain and peripheral organs. The anti-aging genes in people at risk for various diseases in global populations may be defective early in life and not connected to DNA methylation profile associated with aging and longevity [140].

\section{Discussion}

In Western countries and the developing world the metabolic syndrome and NAFLD and neurodegenerative disease has reached approximate $30 \%$ of the global population. Accelerated age related disease associated with cell senescence interfere the anti-aging genes that are involved with cell growth and healthy aging. Dietary interventions with calorie restriction early in life prevent the tissue accumulation of LPS, mycotoxin, xenobiotics and drugs by maintenance of post-prandial lipid metabolism associated with delivery of various foreign compounds to the liver relevant to facilitate many tissue cell to cell communications with the prevention of autonomous organ diseases. Anti-aging strategies that involve nutritional diets allow neuropeptides and endocrine hormones to maintain cell and mitochondrial functions to facilitate nutrient metabolism in the liver and brain. Prevention of insulin resistance has become the major prevention program in global populations with improvement in zinc intake and maintenance of nitric oxide homeostasis in cells central to prevent early alterations in multiple anti-aging genes, neuropeptides and endocrine hormones that are associated with appetite regulation, insulin resistance and cell apoptosis.

\section{Conclusion}

The regulation of food intake and calorie restriction is important to appetite regulation with relevance to the progression of chronic disease and neurodegeneration. Appetite dysregulation involves neurons associated with the suppression of the anti-aging gene Sirt 1 and other anti-aging genes such as Klotho, p66Shc and FOXO1/ FOXO3a that are connected to the programmed cell death (mitochondrial apoptosis) and dysregulation of glucose, lipid and amyloid beta metabolism. Nutritional intervention early in life with the consumption of very low carbohydrate diets has been recommended that allows maintenance of the autonomic innervation of the liver by the brain. In the aging process unhealthy diets disconnect the liver from the brain with the ingestion of LPS, myoctoxin and xenobiotics that induce autonomous liver disease, metabolic disease and neurodegeneration. The brain and liver dysregulation are connected to various chronic diseases associated with abnormal post-prandial lipid metabolism, cardiovascular disease, obesity and diabetes. The anti-aging therapy involves low calorie diets that do not contain LPS, mycotoxin or xenobiotics and these diets maintain brain and liver Sirt 1 activity with appetite regulation closely linked to zinc and nitric oxide homeostasis connected to the autonomic control of the liver by the brain.

\section{Acknowledgements}

This work was supported by grants from Edith Cowan University, the McCusker Alzheimer's Research Foundation and the National Health and Medical Research Council.

\section{References}

[1] Ahima, R.S. and Antwi, D.A. (2008) Brain Regulation of Appetite and Satiety. Endocrinology and Metabolism Clinics 
of North America, 37, 811-823. http://dx.doi.org/10.1016/j.ecl.2008.08.005

[2] King, M.W. (2015) Gut-Brain Interrelationships and Control of Eating Behaviour, 1996-2014, The Medical Biochemistry Page. Org, info@ Last Modified 9 April.

[3] Martins, I.J. (2015) Appetite Dysregulation and Obesity in Western Countries. Lambert Book Appetite, E-Book, First Edited by Jones, E., LAP LAMBERT Academic Publishing, ISBN 978-3-659-40372-9, 2013.

[4] Li, X. (2013) SIRT1 and Energy Metabolism. Acta Biochimica Biophysica Sinica, 45, 51-60. http://dx.doi.org/10.1093/abbs/gms108

[5] Boutant, M. and Cantó, C. (2013) SIRT1 Metabolic Actions: Integrating Recent Advances from Mouse Models. Molecular Metabolism, 3, 5-18. http://dx.doi.org/10.1016/j.molmet.2013.10.006

[6] Chang, H.C. and Guarente, L. (2013) SIRT1 Mediates Central Circadian Control in the SCN by a Mechanism That Decays with Aging. Cell, 153, 1448-1460. http://dx.doi.org/10.1016/j.cell.2013.05.027

[7] Mohawk, J.A. and Takahashi, J.S. (2011) Cell Autonomy and Synchrony of Suprachiasmatic Nucleus Circadian Oscillators. Trends in Neurosciences, 34, 349-358. http://dx.doi.org/10.1016/i.tins.2011.05.003

[8] Cavallaro, S. (2015) Cracking the Code of Neuronal Apoptosis and Survival. Cell Death and Disease, 6, e1963. http://dx.doi.org/10.1038/cddis.2015.309

[9] Portt, L., Norman, G., Clapp, C., Greenwood, M. and Greenwood, M.T. (2011) Anti-Apoptosis and Cell Survival: A Review. Biochimica Biophysica Acta, 1813, 238-259. http://dx.doi.org/10.1016/j.bbamcr.2010.10.010

[10] Morrison, R.S., Kinoshita, Y., Johnson, M.D., Ghatan, S., Ho, J.T. and Garden, G. (2002) Neuronal Survival and Cell Death Signaling Pathways. Advances in Experimental Medicine and Biology, 513, 41-86. http://dx.doi.org/10.1007/978-1-4615-0123-7 2

[11] Martins, I.J. (2015) Nutrition Increases Survival and Reverses NAFLD and Alzheimer's Disease. First Edition Edited by Berdos, A., 01/ 2015, E-Book/Printed Book, LAP LAMBERT, ISBN: 978-3-659-78371-5.

[12] Radziuk, J.M. (2013) The Suprachiasmatic Nucleus, Circadian Clocks, and the Liver. Diabetes, 62, 1017-1019. http://dx.doi.org/10.2337/db12-1765

[13] Zock, P.L. (2007) Postprandial Lipoprotein Metabolism-Pivot or Puzzle? American Journal of Clinical Nutrition, 85 331-332.

[14] Martins, I.J. and Redgrave, T.G. (2004) Obesity and Post-Prandial Lipid Metabolism. Feast or Famine? The Journal of Nutritional Biochemistry, 15, 130-141. http://dx.doi.org/10.1016/j.jnutbio.2003.10.006

[15] Tang, B.L. (2006) SIRT1, Neuronal Cell Survival and the Insulin/IGF-1 Aging Paradox. Neurobiology of Aging, 27, 501-505. http://dx.doi.org/10.1016/j.neurobiolaging.2005.02.001

[16] Tran, D., Bergholz, J., Zhang, H., He, H., Wang, Y., Zhang, Y., Li, Q., Kirkland, J.L. and Xiao, Z.X. (2014) Insulin-Like Growth Factor-1 Regulates the SIRT1-p53 Pathway in Cellular Senescence. Aging Cell, 13, 669-678. http://dx.doi.org/10.1111/acel.12219

[17] Gu, Y., Wang, C. and Cohen, A. (2004) Effect of IGF-1 on the Balance between Autophagy of Dysfunctional Mitochondria and Apoptosis. FEBS Letters, 577, 357-360. http://dx.doi.org/10.1016/j.febslet.2004.10.040

[18] Ribeiro, M., Rosenstock, T.R., Oliveira, A.M., Oliveira, C.R. and Rego, A.C. (2014) Insulin and IGF-1 Improve Mitochondrial Function in a PI-3K/Akt-Dependent Manner and Reduce Mitochondrial Generation of Reactive Oxygen Species in Huntington's Disease Knock-In Striatal Cells. Free Radical Biology Medicine, 74, 129-144. http://dx.doi.org/10.1016/j.freeradbiomed.2014.06.023

[19] Yin, F., Jiang, T. and Cadenas, E. (2013) Metabolic Triad in Brain Aging: Mitochondria, Insulin/IGF-1 Signalling and JNK Signalling. Biochemical Society Transactions, 41, 101-105. http://dx.doi.org/10.1042/BST20120260

[20] Monteserin-Garcia, J., Al-Massadi, O., Seoane, L.M., Alvarez, C.V., Shan, B., Stalla, J., Paez-Pereda, M., Casanueva, F.F., Stalla, G.K. and Theodoropoulou, M. (2013) Sirt1 Inhibits the Transcription Factor CREB to Regulate Pituitary Growth Hormone Synthesis. FASEB Journal, 27, 1561-1571. http://dx.doi.org/10.1096/fj.12-220129

[21] Yamamoto, M., Iguchi, G., Fukuoka, H., Suda, K., Bando, H., Takahashi, M., Nishizawa, H., Seino, S. and Takahashi, Y. (2013) SIRT1 Regulates Adaptive Response of the Growth Hormone-Insulin-Like Growth Factor-I Axis under Fasting Conditions in Liver. Proceedings of the National Academy of Sciences of the United States of America, 110, 14948-14953. http://dx.doi.org/10.1073/pnas.1220606110

[22] Martins, I.J. (2015) Diabetes and Organ Dysfunction in the Developing and Developed World. Global Journal of Medical Research, 15, 14-22.

[23] Martins, I.J. (2015) LPS Regulates Apolipoprotein E and A $\beta$ Interactions with Effects on Acute Phase Proteins and Amyloidosis. Advances in Aging Research, 4, 69-77. http://dx.doi.org/10.4236/aar.2015.42009

[24] Esch, T., Stefano, G.B., Fricchione, G.L. and Benson, H. (2002) Stress-Related Diseases: A Potential Role for Nitric 
Oxide. Medical Science Monitor, 8, RA103-RA118.

[25] Martins, I.J. (2015) Nutritional Diets Accelerate Amyloid Beta Metabolism and Prevent the Induction of Chronic Diseases and Alzheimer's Disease. Photon eBooks, UBN: 015-A94510112017.

[26] Kumari, S., Chaurasia, S.N., Nayak, M.K., Mallick, R.L. and Dash, D. (2015) Sirtuin Inhibition Induces Apoptosis-Like Changes in Platelets and Thrombocytopenia. The Journal of Biological Chemistry, 290, 12290-12299. http://dx.doi.org/10.1074/jbc.M114.615948

[27] Breitenstein, A., Stein, S., Holy, E.W., Camici, G.G., Lohmann, C., Akhmedov, A., Spescha, R., Elliott, P.J., Westphal, C.H., Matter, C.M., Lüscher, T.F. and Tanner, F.C. (2011) Sirt1 Inhibition Promotes in vivo Arterial Thrombosis and Tissue Factor Expression in Stimulated Cells. Cardiovascular Research, 89, 464-472. http://dx.doi.org/10.1093/cvr/cvq339

[28] Chen, L., Feng, Y., Zhou, Y., Zhu, W., Shen, X., Chen, K., Jiang, H. and Liu, D. (2010) Dual Role of Zn ${ }^{2+}$ in Maintaining Structural Integrity and Suppressing Deacetylase Activity of SIRT1. Journal of Inorganic Biochemistry, 104, 180-185. http://dx.doi.org/10.1016/j.jinorgbio.2009.10.021

[29] Gatenby, K.V., Imrie, H. and Kearney, M. (2013) The IGF-1 Receptor and Regulation of Nitric Oxide Bioavailability and Insulin Signalling in the Endothelium. Pflügers Archiv-European Journal of Physiology, 465, 1065-1074. http://dx.doi.org/10.1007/s00424-013-1218-z

[30] Abbas, A., Viswambharan, H., Imrie, H., Rajwani, A., Kahn, M., Gage, M., Cubbon, R., Surr, J., Wheatcroft, S. andKearney, M. (2011) A Endothelial Cell Nitric Oxide Bioavailability and Insulin Sensitivity Are Regulated by IGF-1 and Insulin Receptor Levels. Heart, 97, A1-A2 http://dx.doi.org/10.1136/heartjnl-2011-300110.1

[31] Abbas, A., Imrie, H., Viswambharan, H., Sukumar, P., Rajwani, A., Cubbon, R.M., Gage, M., Smith, J., Galloway, S., Yuldeshava, N., Kahn, M., Xuan, S., Grant, P.J., Channon, K.M., Beech, D.J., Wheatcroft, S.B. and Kearney, M.T. (2011) The Insulin-Like Growth Factor-1 Receptor Is a Negative Regulator of Nitric Oxide Bioavailability and Insulin Sensitivity in the Endothelium. Diabetes, 60, 2169-2178. http://dx.doi.org/10.2337/db11-0197

[32] Galli, G., Pinchera, A., Piaggi, P., Fierabracci, P., Giannetti, M., Querci, G., Scartabelli, G., Manetti, L., Ceccarini, G., Martinelli, S., Di Salvo, C., Anselmino, M., Bogazzi, F., Landi, A., Vitti, P., Maffei, M. and Santini, F. (2012) Serum Insulin-Like Growth Factor-1 Concentrations Are Reduced in Severely Obese Women and Raise after Weight Loss Induced by Laparoscopic Adjustable Gastric Banding. Obesity Surgery, 22, 1276-1280. http://dx.doi.org/10.1007/s11695-012-0669-1

[33] Tuncel, D., Tolun, F.I. and Toru, I. (2009) Serum Insulin-Like Growth Factor-1 and Nitric Oxide Levels in Parkinson's Disease. Mediators of Inflammation, 2009, Article ID: 132464.

[34] Zheng, W.H., Kar, S., Doré, S. and Quirion, R. (2000) Insulin-Like Growth Factor-1 (IGF-1): A Neuroprotective Trophic Factor Acting via the Akt Kinase Pathway. Journal of Neural Transmission Supplementation, 60, 261-272. http://dx.doi.org/10.1007/978-3-7091-6301-6_17

[35] Zheng, W.H. and Quirion, R. (2004) Comparative Signaling Pathways of Insulin-Like Growth Factor-1 and Brain-Derived Neurotrophic Factor in Hippocampal Neurons and the Role of the PI3 Kinase Pathway in Cell Survival. Journal of Neurochemistry, 89, 844-852. http://dx.doi.org/10.1111/j.1471-4159.2004.02350.x

[36] Carro, E. and Torres-Aleman, I. (2009) Insulin-Like Growth Factor I and Alzheimer's Disease: Therapeutic Prospects? Biochemical Biophysica Research Communications, 385, 434-438.

[37] Alves, C.X., Vale, S.H., Dantas, M.M., Maia, A.A., Franca, M.C., Marchini, J.S, Leite, L.D. and Brandao-Neto, J. (2012) Positive Effects of Zinc Supplementation on Growth, GH, IGF1, and IGFBP3 in Eutrophic Children. Journal Pediatry Endocrinology Metabolism, 25, 881-887. http://dx.doi.org/10.1515/jpem-2012-0120

[38] Rocha, É.D., de Brito, N.J., Dantas, M.M., Silva, A., Almeida, M. and Brandão-Neto, J. (2015) Effect of Zinc Supplementation on GH, IGF1, IGFBP3, OCN, and ALP in Non-Zinc-Deficient Children. Journal of the American College of Nutrition, 34, 290-299. http://dx.doi.org/10.1080/07315724.2014.929511

[39] Wan, Y., Petris, M.J. and Peck, S.C. (2014) Separation of Zinc-Dependent and Zinc-Independent Events during Early LPS-Stimulated TLR4 Signaling in Macrophage Cells. FEBS Letters, 588, 2928-2935. http://dx.doi.org/10.1016/j.febslet.2014.05.043

[40] Haase, H., Ober-Blöbaum, J.L., Engelhardt, G., Hebel, S., Heit, A., Heine, H. and Rink, L. (2008) Zinc Signals Are Essential for Lipopolysaccharide-Induced Signal Transduction in Monocytes. Journal of Immunology, 181, 6491-6502. http://dx.doi.org/10.4049/jimmunol.181.9.6491

[41] Anubhuti, A.S. (2006) Role of Neuropeptides in Appetite Regulation and Obesity: A Review. Neuropeptides, 40, 375401. http://dx.doi.org/10.1016/j.npep.2006.07.001

[42] Baranowska, B., Wolinska-Witort, E., Wasilewska-Dziubinska, E., Roguski, K., Martynska, L. and Chmielowska, M. (2003) The Role of Neuropeptides in the Disturbed Control of Appetite and Hormone Secretion in Eating Disorders. Neuroendocrinology Letters, 24, 431-434. 
[43] Nyberg, F. (2011) Neuropeptides in Neuroprotection and Neuroregeneration. June 2012 by CRC Press, 319 Pages - 4 Color \& 81 B/W Illustrations, ISBN: 9781439830628.

[44] Sharma, R.K. and Sethi, A. (2011) Klotho An Anti-Aging Gene. International Journal of Pharma and Bio Sciences, 2 , 497-507.

[45] Yamamoto, M., Clark, J.D., Pastor, J.V., Gurnani, P., Nandi, A., Kurosu, H., Miyoshi, M., Ogawa, Y., Castrillon, D.H., Rosenblatt, K.P. and Kuro-o, M. (2005) Anti-Aging Hormone Klotho Regulation of Oxidative Stress by the Mechanisms of Signal Transduction. The Journal of Biological Chemistry, 280, 38029-38034. http://dx.doi.org/10.1074/jbc.M509039200

[46] Hsua, S.-C., Huanga, S.-M, Chena, A., Sund, C.-Y., Lina, S.-H., Chena, J.-H., Liub, S.-T. and Hsua, Y.-J. (2014) Resveratrol Increases Anti-Aging Klotho Gene Expression via the Activating Transcription Factor 3/c-Jun Complex-Mediated Signaling Pathway. The International Journal of Biochemistry \& Cell Biology, 53, 361-371. http://dx.doi.org/10.1016/j.biocel.2014.06.002

[47] de Oliveira, R.M. (2006) Klotho RNAi Induces Premature Senescence of Human Cells via a p53/p21 Dependent Pathway. FEBS Letters, 580, 5753-5758. http://dx.doi.org/10.1016/j.febslet.2006.09.036

[48] Lee, J., Jeong, D.-J., Kim, J., Lee, S., Park, J.-H., Chang, B., Jung, S.-I., et al. (2010) The Anti-Aging Gene KLOTHO Is a Novel Target for Epigenetic Silencing in Human Cervical Carcinoma. Molecular Cancer, 9, 109. http://dx.doi.org/10.1186/1476-4598-9-109

[49] Wolf, I., Levanon-Cohen, S., Bose, S., Ligumsky, H., Sredni, B., Kanety, H., Kuro-o, M., Karlan, B., Kaufman, B., Koeffler, H.P. and Rubinek, T. (2008) Klotho: A Tumor Suppressor and a Modulator of the IGF-1 and FGF Pathways in Human Breast Cancer. Oncogene, 27, 7094-7105. http://dx.doi.org/10.1038/onc.2008.292

[50] Bartke, A. (2006) Long-Lived Klotho Mice: New Insights into the Roles of IGF-1 and Insulin in Aging. Trends in Endocrinology and Metabolism, 17, 33-35. http://dx.doi.org/10.1016/j.tem.2006.01.002

[51] Zhang, F., Kato, B.S., Gardner, J.P., Kimura, M., Spector, T.D. and Ahmadi, K.R. (2007) Lack of Association between Leukocyte Telomere Length and Genetic Variants in Two Ageing-Related Candidate Genes. Mechanisms of Ageing Development, 128, 415-422. http://dx.doi.org/10.1016/j.mad.2007.05.007

[52] Dubal, D.B. (2014) Life Extension Factor Klotho Enhances Cognition. Cell Reports, 7, 1065-1076. http://dx.doi.org/10.1016/j.celrep.2014.03.076

[53] Drüeke, T.B. and Massy, Z.A. (2013) Circulating Klotho Levels: Clinical Relevance and Relationship with Tissue Klotho Expression. Kidney International, 83, 13-15. http://dx.doi.org/10.1038/ki.2012.370

[54] Trinei, M., Berniakovich, I., Beltrami, E., Migliaccio, E., Fassina, A., Pelicci, P.G. and Giorgio, M. (2009) p66Shc Signals to Age. $A G I N G, 1,503-510$.

[55] Bhat, S.S., Anand, D. and Khanday, F.A. (2015) p66Shc as a Switch in Bringing about Contrasting Responses in Cell Growth: Implications on Cell Proliferation and Apoptosis. Molecular Cancer, 14, 76. http://dx.doi.org/10.1186/s12943-015-0354-9

[56] Skulachev, V.P. (2000) The p66Shc Protein: A Mediator of the Programmed Death of an Organism? IUBMB Life, 49, 177-180. http://dx.doi.org/10.1080/713803613

[57] Migliaccio, E., Giorgio, M. and Pelicci, P.G. (2013) P53 and Aging: Role of p66Shc. Aging (Albany NY), 5, $488-489$.

[58] Zlotorynski, E. (2014) P66Shc Inhibits Anabolic Metabolism. Nature Reviews Molecular Cell Biology, 15, 222.

[59] Soliman, M.A., Rahman, A.M.A., Lamming, D.A., Birsoy, K., Pawling, J., Frigolet, M.E., Lu, H., Fantus, I.G., Pasculescu, A., Zheng, Y., Sabatini, D.M., Dennis, J.W. and Pawson, T. (2014) The Adaptor Protein p66Shc Inhibits mTOR-Dependent Anabolic Metabolism. Science Signal, 7, ra17. http://dx.doi.org/10.1126/scisignal.2004785

[60] Sun, L., Xiao, L., Nie, J., Liu, F.Y., Ling, G.H., Zhu, X.J., Tang, W.B., Chen, W.C., Xia, Y.C., Zhan, M., Ma, M.M., Peng, Y.M., Liu, H., Liu, Y.H. and Kanwar, Y.S. (2010) p66Shc Mediates High-Glucose and Angiotensin II-Induced Oxidative Stress Renal Tubular Injury via Mitochondrial-Dependent Apoptotic Pathway. American Journal of Physiology Renal Physiology, 299, F1014-F1025. http://dx.doi.org/10.1152/ajprenal.00414.2010

[61] Graiani, G., Lagrasta, C., Migliaccio, E., Spillmann, F., Meloni, M., Madeddu, P., Quaini, F., Padura, I.M., Lanfrancone, L., Pelicci, P. and Emanueli, C. (2005) Genetic Deletion of the p66Shc Adaptor Protein Protects from Angiotensin II-Induced Myocardial Damage. Hypertension, 46, 433-440. http://dx.doi.org/10.1161/01.HYP.0000174986.73346.ba

[62] De Marchi, E., Baldassari, F., Bononi, A., Wieckowski, M.R. and Pinton, P. (2013) Oxidative Stress in Cardiovascular Diseases and Obesity: Role of p66Shc and Protein Kinase C. Oxidative Medicine and Cellular Longevity, 2013, Article ID: 564961. http://dx.doi.org/10.1155/2013/564961

[63] Spescha, R.D., Klohs, J., Semerano, A., Giacalone, G., Derungs, R.S., Reiner, M.F., Gutierrez, D.R., Mendez-Carmona, N., et al. (2015) Post-Ischaemic Silencing of p66Shc Reduces Ischaemia/Reperfusion Brain Injury and Its Ex- 
pression Correlates to Clinical Outcome in Stroke. European Heart Journal, 36, 1590-1600.

http://dx.doi.org/10.1093/eurheartj/ehv140

[64] Spescha, R.D., Shi, Y., Wegener, S., Keller, S., Weber, B., Wyss, M.M., Lauinger, N., Tabatabai, G., Paneni, F., Cosentino, F., Hock, C., Weller, M., Nitsch, R.M, Lüscher, T.F. and Camici, G.G. (2013) Deletion of the Ageing Gene p66Shc Reduces Early Stroke Size Following Ischaemia/Reperfusion Brain Injury. European Heart Journal, 34, 96103. http://dx.doi.org/10.1093/eurheartj/ehs331

[65] Natalicchio, A., Tortosa, F., Perrini, S., Laviola, L. and Giorgino, F. (2011) p66Shc, a Multifaceted Protein Linking Erk Signalling, Glucose Metabolism, and Oxidative Stress. Archives of Physiology and Biochemistry, 117, 116-124. http://dx.doi.org/10.3109/13813455.2011.562513

[66] Kim, Y.R., Kim, C.S., Naqvi, A., Kumar, A., Kumar, S., Hoffman, T.A. and Irani, K. (2012) Epigenetic Upregulation of p66Shc Mediates Low-Density Lipoprotein Cholesterol-Induced Endothelial Cell Dysfunction. American Journal of Physiology: Heart and Circulatory Physiology, 303, H189-H196. http://dx.doi.org/10.1152/ajpheart.01218.2011

[67] Berniakovich, I., Trinei, M., Stendardo, M., Migliaccio, E., Minucci, S., Bernardi, P., Pelicci, P.G. and Giorgio, M. (2008) p66Shc-Generated Oxidative Signal Promotes Fat Accumulation. The Journal of Biological Chemistry, 283, 34283-34293. http://dx.doi.org/10.1074/jbc.M804362200

[68] Giovannini, C., Scazzocchio, B., Matarrese, P., Varì, R., D’Archivio, M., Di Benedetto, R., Casciani, S., Dessì, M.R., Straface, E., Malorni, W. and Masella, R. (2008) Apoptosis Induced by Oxidized Lipids Is Associated with Up-Regulation of p66Shc in Intestinal Caco-2 Cells: Protective Effects of Phenolic Compounds. Journal of Nutritional Biochemistry, 19, 118-128. http://dx.doi.org/10.1016/i.jnutbio.2007.01.010

[69] Favetta, L.A., Robert, C., King, W.A. and Betts, D.H. (2004) Expression Profiles of p53 and p66Shc during Oxidative Stress-Induced Senescence in Fetal Bovine Fibroblasts. Experimental Cell Research, 299, 36-48. http://dx.doi.org/10.1016/j.yexcr.2004.05.009

[70] Ziolkowski, W., Flis, D.J., Halon, M., Vadhana, D.M., Olek, R.A., Carloni, M., Antosiewicz, J., Kaczor, J.J. and Gabbianelli, R. (2015) Prolonged Swimming Promotes Cellular Oxidative Stress and p66Shc Phosphorylation, but Does Not Induce Oxidative Stress in Mitochondria in the Rat Heart. Free Radical Research, 49, 7-16. http://dx.doi.org/10.3109/10715762.2014.968147

[71] Trinei, M., Giorgio, M., Cicalese, A., Barozzi, S. and Ventura, A. (2002) A p53-p66Shc Signalling Pathway Controls Intracellular Redox Status, Levels of Oxidation-Damaged DNA and Oxidative Stress-Induced Apoptosis. Oncogene, 21, 3872-3878. http://dx.doi.org/10.1038/sj.onc.1205513

[72] Kim, C.-S., Jung, S.-B., Naqvi, A., Hoffman, T.A., DeRicco, J., Yamamori, T., Cole, M.P., Jeon, B.H. and Irani, K. (2008) P53 Impairs Endothelium-Dependent Vasomotor Function through Transcriptional Upregulation of p66Shc. Circulation Research, 103, 1441-1450. http://dx.doi.org/10.1161/CIRCRESAHA.108.181644

[73] Zhou, S., Chen, H.Z., Wan, Y.Z., Zhang, Q.J., Wei, Y.S., Huang, S., Liu, J.J., Lu, Y.B., Zhang, Z.Q., Yang, R.F., Zhang, R., Cai, H., Liu, D.P. and Liang, C.C. (2011) Repression of p66Shc Expression by SIRT1 Contributes to the Prevention of Hyperglycemia-Induced Endothelial Dysfunction. Circulation Research, 109, 639-648. http://dx.doi.org/10.1161/CIRCRESAHA.111.243592

[74] Natalicchio, A., Tortosa, F., Labarbuta, R., Biondi, G., Marrano, N. and Carchia, E. (2015) The p66Shc Redox Adaptor Protein Is Induced by Saturated Fatty Acids and Mediates Lipotoxicity-Induced Apoptosis in Pancreatic Beta Cells. Diabetologia, 58, 1260-1271. http://dx.doi.org/10.1007/s00125-015-3563-2

[75] Smith, W.W., Norton, D.D., Gorospe, M., Jiang, H., Nemoto, S., Holbrook, N.J., Finkel, T. and Kusiak, J.W. (2005) Phosphorylation of p66Shc and Forkhead Proteins Mediates A Beta Toxicity. Journal of Cell Biology, 169, 331-339. http://dx.doi.org/10.1083/jcb.200410041

[76] Bashir, M., Parray, A.A., Baba, R.A., Bhat, H.F., Bhat, S.S., Mushtaq, U., Andrabi, K.I. and Khanday, F.A. (2014) $\beta$-Amyloid-Evoked Apoptotic Cell Death Is Mediated through MKK6-p66Shc Pathway. Neuromolecular Medicine, 16, 137-149. http://dx.doi.org/10.1007/s12017-013-8268-4

[77] Martins, I.J. (2015) Unhealthy Diets Determine Benign or Toxic Amyloid Beta States and Promote Brain Amyloid Beta Aggregation. Austin Journal of Clinical Neurology, 2, 1060-1066.

[78] Martins, I.J. (2015) Diabetes and Cholesterol Dyshomeostasis Involve Abnormal $\alpha$-Synuclein and Amyloid Beta Transport in Neurodegenerative Diseases. Austin Alzheimer's Journal of Parkinsons Disease, 2, 1020-1028.

[79] Martins, I.J. (2015) Unhealthy Nutrigenomic Diets Accelerate NAFLD and Adiposity in Global Communities. Journal of Molecular and Genetic Medicine, 9, 1-11.

[80] Ausserlechner, M.J., Hagenbuchner, J., Fuchs, S., Geiger, K. and Obexer, P. (2012) FOXO Transcription Factors as Potential Therapeutic Targets in Neuroblastoma Neuroblastoma. Present and Future Edited by Prof. Shimada, H., ISBN: 978-953-307-016-2, Hard Cover, 366 p, Publisher InTech, Published Online. 
[81] Shang, Y.C., Chong, Z.Z., Hou, J. and Maiese, K. (2009) The Forkhead Transcription Factor FOXO3a Controls Microglial Inflammatory Activation and Eventual Apoptotic Injury through Caspase 3. Current Neurovascular Research, 6, 20-31. http://dx.doi.org/10.2174/156720209787466064

[82] Gilley, J., Coffer, P.J. and Ham, J. (2003) FOXO Transcription Factors Directly Activate Bim Gene Expression and Promote Apoptosis in Sympathetic Neurons. Journal of Cell Biology, 162, 613-622. http://dx.doi.org/10.1083/jcb.200303026

[83] Gross, D.N., van den Heuvel, A.P.J. and Birnbaum, M.J. (2008) The Role of FoxO in the Regulation of Metabolism. Oncogene, 27, 2320-2336. http://dx.doi.org/10.1038/onc.2008.25

[84] Zhu, W., Bijur, G.N., Styles, N.A. and Li, X. (2004) Regulation of FOXO3a by Brain-Derived Neurotrophic Factor in Differentiated Human SH-SY5Y Neuroblastoma Cells. Molecular Brain Research, 126, 45-56. http://dx.doi.org/10.1016/j.molbrainres.2004.03.019

[85] Brunet, A., et al. (2004) Stress-Dependent Regulation of FOXO Transcription Factors by the SIRT1 Deacetylase. Science, 303, 2011-2015. http://dx.doi.org/10.1126/science.1094637

[86] Hori, Y.S., Kuno, A., Hosoda, R. and Horio, Y. (2013) Regulation of FOXOs and p53 by SIRT1 Modulators under Oxidative Stress. PLoS ONE, 8, e73875. http://dx.doi.org/10.1371/journal.pone.0073875

[87] Shemi, D., Azab, A.N. and Kaplanski, J. (2000) Time-Dependent Effect of LPS on PGE2 and TNF-Alpha Production by Rat Glial Brain Culture: Influence of COX and Cytokine Inhibitors. Journal of Endotoxin Research, 6, 377-381.

[88] Henkel, J., Frede, K., Schanze, N., Vogel, H., Schürmann, A., Spruss, A., Bergheim, I. and Püschel, G.P. (2012) Stimulation of Fat Accumulation in Hepatocytes by $\mathrm{PGE}_{2}$-Dependent Repression of Hepatic Lipolysis, $\beta$-Oxidation and VLDL-Synthesis. Laboratory Investigation, 92, 1597-1606. http://dx.doi.org/10.1038/labinvest.2012.128

[89] Boucher, J., Charalambous, M., Zarse, K., Mori, M.A., Kleinridders, A., Ristow, M., Ferguson-Smith, A.C. and Kahn, C.R. (2014) Insulin and Insulin-Like Growth Factor 1 Receptors Are Required for Normal Expression of Imprinted Genes. Proceedings of the National Academy of Sciences of the United States of America, 111, 14512-14517. http://dx.doi.org/10.1073/pnas.1415475111

[90] Djiogue, S., Kamdje, A.H.N., Vecchio, L., Kipanyula, M.J., Farahna, M., Aldebasi, Y. and Etet, P.F.S. (2013) Insulin Resistance and Cancer: The Role of Insulin and IGFs. Endocrine Related Cancer, 20, R1-R17. http://dx.doi.org/10.1530/ERC-12-0324

[91] Arcidiacono, B., Iiritano, S., Nocera, A., Possidente, K., Nevolo, M.T., Ventura, V., Foti, D., Chiefari, E. and Brunetti, A. (2012) Insulin Resistance and Cancer Risk: An Overview of the Pathogenetic Mechanisms. Experimental Diabetes Research, 2012, Article ID: 789174.

[92] Hallett, P.J., McLean, J.R., Kartunen, A., Langston, J.W. and Isacson, O. (2012) Alpha-Synuclein Overexpressing Transgenic Mice Show Internalorgan Pathology and Autonomic Deficits. Neurobiology Disease, 47, 258-267. http://dx.doi.org/10.1016/j.nbd.2012.04.009

[93] Tai, Y., Chen, L., Huang, E., Liu, C., Yang, X., Qiu, P. and Wang, H. (2014),Protective Effect of Alpha-Synuclein Knockdown on Methamphetamine-Induced Neurotoxicity in Dopaminergic Neurons. Neural Regeneration Research, 9 , 951-958. http://dx.doi.org/10.4103/1673-5374.133146

[94] Kao, S.Y. (2011) Rescue of Alpha-Synuclein Cytotoxicity by Insulin-Like Growth Factors. Neurosignals, 19, 86-96.

[95] Chung, J.Y., Lee, S.J., Lee, S.H., Jung, Y.S., Ha, N.C., Seol, W. and Park, B.J. (2011) Direct Interaction of $\alpha$-Synuclein and AKT Regulates IGF-1 Signaling: Implication of Parkinson Disease. Neurosignals, 19, 86-96. http://dx.doi.org/10.1159/000325028

[96] Martins, I.J., Creegan, R., Lim, W.L.F. and Martins, R.N. (2013) Molecular Insights into Appetite Control and Neuroendocrine Disease as Risk Factors for Chronic Diseases in Western Countries. Open Journal of Endocrine and Metabolic Diseases, 3, 11-33. http://dx.doi.org/10.4236/ojemd.2013.35A002

[97] Liu, J., Shen, W., Zhao, B., Wang, Y., Wertz, K., Weber, P. and Zhang, P. (2009) Targeting Mitochondrial Biogenesis for Preventing and Treating Insulin Resistance in Diabetes and Obesity: Hope from Natural Mitochondrial Nutrients. Advanced Drug Delivery Reviews, 61, 1343-1352. http://dx.doi.org/10.1016/j.addr.2009.06.007

[98] Zamora, M. and Villena, J.A. (2014) Targeting Mitochondrial Biogenesis to Treat Insulin Resistance. Current Pharmaceutical Design, 20, 5527-5557. http://dx.doi.org/10.2174/1381612820666140306102514

[99] Brown, G.C. (1999) Nitric Oxide and Mitochondrial Respiration. Biochimica Biophysica Acta, 1411, 351-369. http://dx.doi.org/10.1016/S0005-2728(99)00025-0

[100] Nisoli, E. and Carruba, M.O. (2006) Nitric Oxide and Mitochondrial Biogenesis. Journal of Cell Science, 119, 28552862. http://dx.doi.org/10.1242/jcs.03062

[101] Yi, C.X., la Fleur, S.E., Fliers, E. and Kalsbeek, A. (2010) The Role of the Autonomic Nervous Liver Innervation in the Control of Energy Metabolism. Biochimica Biophysica Acta, 1802, 416-431. 
http://dx.doi.org/10.1016/j.bbadis.2010.01.006

[102] Xu, M., Iwasaki, T., Shimokawa, N., Sajdel-Sulkowska, E.M. and Koibuchi, N. (2013) The Effect of Low Dose Lipopolysaccharide on Thyroid Hormone-Regulated Actin Cytoskeleton Modulation and Type 2 Iodothyronine Deiodinase Activity in Astrocytes. Endocrine Journal, 60, 1221-1230. http://dx.doi.org/10.1507/endocrj.EJ13-0294

[103] Vélez, M.L., Costamagna, E., Kimura, E.T., Fozzatti, L., Pellizas, C.G., Montesinos, M.M., Lucero, A.M., Coleoni, A.H., Santisteban, P. and Masini-Repiso, A.M. (2006) Bacterial Lipopolysaccharide Stimulates the Thyrotropin-Dependent Thyroglobulin Gene Expression at the Transcriptional Level by Involving the Transcription Factors Thyroid Transcription Factor-1 and Paired Box Domain Transcription Factor 8. Endocrinology, 147, 3260-3275. http://dx.doi.org/10.1210/en.2005-0789

[104] Stafford, J.M., Yu, F., Printz, R., Hasty, A.H., Swift, L.L. and Niswender, K.D. (2008) Central Nervous System Neuropeptide Y Signaling Modulates VLDL Triglyceride Secretion. Diabetes, 57, 1482-1490. http://dx.doi.org/10.2337/db07-1702

[105] Rojas, J.M., Bruinstroop, E., Printz, R.L., Alijagic-Boers, A., Foppen, E., Turney, M.K., George, L., Beck-Sickinger, A.-G, Kalsbeek, A. and Niswender, K.D. (2015) Central Nervous System Neuropeptide Y Regulates Mediators of Hepatic Phospholipid Remodeling and Very Low-Density Lipoprotein Triglyceride Secretion via Sympathetic Innervation. Molecular Metabolism, 4, 210-221. http://dx.doi.org/10.1016/j.molmet.2015.01.004

[106] Ng, F., Wijaya, L. and Tang, B.L. (2015) SIRT1 in the Brain-Connections with Aging-Associated Disorders and Lifespan. Frontier Cell Neuroscience, 9, 64. http://dx.doi.org/10.3389/fncel.2015.00064

[107] Zocchi, L. and Sassone-Corsi, P. (2012) SIRT1-Mediated Deacetylation of MeCP2 Contributes to BDNF Expression. Epigenetics, 7, 695-700. http://dx.doi.org/10.4161/epi.20733

[108] Jeong, H., Cohen, D.E., Cui, L., Supinski, A., Savas, J.N., Mazzulli, J.R., Yates, J.R., Bordone, L., Guarente, L. and Krainc, D. (2011) Sirt1 Mediates Neuroprotection from Mutant Huntingtin by Activation of the TORC1 and CREB Transcriptional Pathway. Nature Medicine, 18, 159-165. http://dx.doi.org/10.1038/nm.2559

[109] Xapelli, S., Bernardino, L., Ferreira, R., Grade, S., Silva, A.P., Salgado, J.R., Cavadas, C., Grouzmann, E., Poulsen, F.R., Jakobsen, B., Oliveira, C.R. and Zimmer, J. (2008) Interaction between Neuropeptide Y (NPY) and Brain-Derived Neurotrophic Factor in NPY-Mediated Neuroprotection against Excitotoxicity: A Role for Microglia. European Journal of Neuroscience, 27, 2089-2102. http://dx.doi.org/10.1111/j.1460-9568.2008.06172.X

[110] Reibel, S., Vivien-Roels, B., Lê, B.T., Larmet, Y., Carnahan, J., Marescaux, C. and Depaulis, A. (2000) Overexpression of Neuropeptide Y Induced by Brain-Derived Neurotrophic Factor in the Rat Hippocampus Is Long Lasting. European Journal of Neuroscience, 12, 595-605. http://dx.doi.org/10.1046/j.1460-9568.2000.00941.x

[111] Golden, E., Emiliano, A., Maudsley, S., Windham, B.G., Carlson, O.D. and Egan, J.M. (2010) Circulating Brain-Derived Neurotrophic Factor and Indices of Metabolic and Cardiovascular Health: Data from the Baltimore Longitudinal Study of Aging. PLOS ONE, 5, e10099. http://dx.doi.org/10.1371/journal.pone.0010099

[112] Lee, R.G., Rains, T.M., Tovar-Palacio, C., Beverly, J.L. and Shay, N.F. (1998) Zinc Deficiency Increases Hypothalamic Neuropeptide Y and Neuropeptide Y mRNA Levels and Does Not Block Neuropeptide Y-Induced Feeding in Rats. Journal of Nutrition, 128, 1218-1223.

[113] Williamson, P.S., Browning, J.D., Sullivan, M.J., O’Dell, B.L. and Macdonald, R.S. (2002) Neuropeptide Y Fails to Normalize Food Intake in Zinc-Deficient Rats. Nutrition Neuroscience, 5, 19-25. http://dx.doi.org/10.1080/10284150290007100

[114] Puca, R., Nardinocchi, L., Porru, M., Simon, A.J., Rechavi, G., Leonetti, C., Givol, D. and D’Orazi, G. (2011) Restoring p53 Active Conformation by Zinc Increases the Response of Mutant p53 Tumor Cells to Anticancer Drugs. Cell Cycle, 10, 1679-1689. http://dx.doi.org/10.4161/cc.10.10.15642

[115] Shen, L., Tso, P., Woods, S.C., Clegg, D.J., Barber, K.L., Carey, K. and Liu, M. (2008) Brain Apolipoprotein E: An Important Regulator of Food Intake in Rats. Diabetes, 57, 2092-2098. http://dx.doi.org/10.2337/db08-0291

[116] Shen, L., Tso, P., Wang, D.Q., Woods, S.C., Davidson, W.S., Sakai, R. and Liu, M. (2009) Up-Regulation of Apolipoprotein E by Leptin in the Hypothalamus of Mice and Rats. Physiology Behaviour, 98, 223-228. http://dx.doi.org/10.1016/j.physbeh.2009.05.013

[117] Knight, D.S., Mahajan, D.K. and Qiao, X. (2001) Dietary Fat Up-Regulates the Apolipoprotein E mRNA Level in the Zucker Lean Rat Brain. Neuroreport, 12, 3111-3115. http://dx.doi.org/10.1097/00001756-200110080-00026

[118] Mastronardi, C.A., Yu, W.H., Srivastava, V.K., Dees, W.L. and McCann, S.M. (2001) Lipopolysaccharide-Induced Leptin Release Is Neurally Controlled. Proceedings of the National Academy of Sciences of the United States of America, 98, 14720-14725. http://dx.doi.org/10.1073/pnas.251543598

[119] Sachot, C., Poole, S. and Luheshi, G.N. (2004) Circulating Leptin Mediates Lipopolysaccharide-Induced Anorexia and Fever in Rats. Journal of Physiology, 561, 263-272. http://dx.doi.org/10.1113/jphysiol.2004.074351

[120]Zu, L., He, J., Jiang, H., Xu, C., Pu, S. and Xu, G. (2009) Bacterial Endotoxin Stimulates Adipose Lipolysis via Toll- 
Like Receptor 4 and Extracellular Signal-Regulated Kinase Pathway. Journal of Biological Chemistry, 284, 5915-5926. http://dx.doi.org/10.1074/jbc.M807852200

[121] Hunter, D.J. (2005) Gene-Environment Interactions in Human Diseases. Nature Reveiw Genetics, 6, 287-298. http://dx.doi.org/10.1038/nrg1578

[122] Martins, I.J. (2013) Increased Risk for Obesity and Diabetes with Neurodegeneration in Developing Countries. Journal of Molecular and Genetic Medicine, S1, 001.

[123] Martins, I.J. (2014) Induction of NAFLD with Increased Risk of Obesity and Chronic Diseases in Developed Countries. Open Journal of Endocrine and Metabolic Diseases, 4, 90-110. http://dx.doi.org/10.4236/ojemd.2014.44011

[124] Scott, M.J., Liu, S., Su, G.L., Vodovotz, Y. and Billiar, T.R. (2005) Hepatocytes Enhance Effects of Lipopolysaccharide on Liver Nonparenchymal Cells through Close Cell Interactions. Shock, 23, 453-458. http://dx.doi.org/10.1097/01.shk.0000160939.08385.f1

[125] Qatanani, M. and Lazar, M.A. (2007) Mechanisms of Obesity-Associated Insulin Resistance: Many Choices on the Menu. Genes Development, 21, 1443-1455. http://dx.doi.org/10.1101/gad.1550907

[126] Belosludtsev, K., Saris, N.E., Andersson, L.C., Belosludtseva, N., Agafonov, A., Sharma, A., Moshkov, D.A. and Mironova, G.D. (2006) On the Mechanism of Palmitic Acid-Induced Apoptosis: The Role of a Pore Induced by Palmitic Acid and $\mathrm{Ca}^{2+}$ in Mitochondria. Journal of Bioenergetics and Biomembranes, 38, 113-120. http://dx.doi.org/10.1007/s10863-006-9010-9

[127] Darzi, J., Frost, G.S. and Robertson, M.D. (2011) Do SCFA Have a Role in Appetite Regulation? Proceedings of the Nutrition Society, 70, 119-128. http://dx.doi.org/10.1017/s0029665110004039

[128] Frost, G., Sleeth, M.L., Sahuri-Arisoylu, M., Lizarbe, B., Cerdan, S., Brody, L., Anastasovska, J., Ghourab, S., Hankir, M., Zhang, S., Carling, D., Swann, J.R., Gibson, G., Viardot, A., Morrison, D., Louise, T.E. and Bell, J.D. (2014) The Short-Chain Fatty Acid Acetate Reduces Appetite via a Central Homeostatic Mechanism. Nature Communications, 5, 3611. http://dx.doi.org/10.1038/ncomms4611

[129] Licciardi, P.V., Ververis, K. and Karagiannis, T.C. (2011) Histone Deacetylase Inhibition and Dietary Short-Chain Fatty Acids. International Scholarly Research Network ISRN Allergy, 2011, Article ID: 869647.

[130] Pouillart, P.R. (1998) Role of Butyric Acid and Its Derivatives in the Treatment of Colorectal Cancer and Hemoglobinopathies. Life Science, 63, 1739-1760. http://dx.doi.org/10.1016/S0024-3205(98)00279-3

[131] Gasior, M., Rogawski, M.A. and Hartman, A.L. (2006) Neuroprotective and Disease-Modifying Effects of the Ketogenic Diet. Behavioural Pharmacology, 17, 431-439. http://dx.doi.org/10.1097/00008877-200609000-00009

[132] Magenta, A., Greco, S., Capogrossi, M.C., Gaetano, C. and Martelli, F. (2014) Nitric Oxide, Oxidative Stress, and p66Shc Interplay in Diabetic Endothelial Dysfunction. BioMed Research International, 2014, Article ID: 193095. http://dx.doi.org/10.1155/2014/193095

[133] Litvinova, L., Atochin, D.N., Fattakhov, N., Vasilenko, M., Zatolokin, P. and Kirienkova, E. (2015) Nitric Oxide and Mitochondria in Metabolic Syndrome. Frontier Physiology, 17, 20.

[134] Morley, J.E., Farr, S.A, Sell, R.L., Hileman, S.M. and Banks, W.A. (2011) Nitric Oxide Is a Central Component in Neuropeptide Regulation of Appetite. Peptides, 32, 776-780. http://dx.doi.org/10.1016/j.peptides.2010.12.015

[135] Vieira, H. and Kroemer, G. (2003) Mitochondria as Targets of Apoptosis Regulation by Nitric Oxide. IUBMB Life, 55, 613-616. http://dx.doi.org/10.1080/15216540310001639652

[136] Stokkan, K.A., Yamazaki, S., Tei, H., Sakaki, Y. and Menaker, M. (2001) Entrainment of the Circadian Clock in the Liver by Feeding. Science, 291, 490-493. http://dx.doi.org/10.1126/science.291.5503.490

[137] Martins, I.J. (2015) Overnutrition Determines LPS Regulation of Mycotoxin Induced Neurotoxicity in Neurodegenerative Diseases. International Journal of Molecular Science, 16, 29554-29573. http://dx.doi.org/10.3390/ijms161226190

[138] Martins, I.J, Mortimer, B.C., Miller, J. and Redgrave, T.G. (1996) Effects of Particle Size and Number on the Plasma Clearance of Chylomicrons and Remnants. Journal of Lipid Research, 37, 2696-2705.

[139] Martins, I.J. (2015) Nutritional and Genotoxic Stress Contributes to Diabetes and Neurodegenerative Diseases Such as Parkinson's and Alzheimer's Diseases. In: Atta-ur-Rahma, Eds., Frontiers in Clinical Drug Research—CNS and Neurological Disorders, Vol. 3, Bentham Science Publishers, Sharjah, 158-192.

[140] Gentilini, D., Mari, D., Castaldi, D., Remondini, D., Ogliari, G., Ostan, R., Bucci, L., Sirchia, S.M., Tabano, S., Cavagnini, F., Monti, D., Franceschi, C., Di Blasio, A.M. and Vitale, G. (2013) Role of Epigenetics in Human Aging and Longevity: Genome-Wide DNA Methylation Profile in Centenarians and Centenarians' Offspring. Age (Dordr), 35, 1961-1973. http://dx.doi.org/10.1007/s11357-012-9463-1 